\title{
Molecular Diversity in Lactuca Species Using Isozymes and RAPD Markers
}

Reda H. Helmy Sammour ( $\square$ rsammour@ksu.edu.sa )

King Saud University https://orcid.org/0000-0002-0014-857X

A-Z. A. Mustafa

King Saud University

M. El-Esawi

King Saud University

\section{Research Article}

Keywords: Lactuca species, isozymes, RAPD markers, corresponding analysis, Cluster analysis

Posted Date: February 19th, 2021

DOl: https://doi.org/10.21203/rs.3.rs-221342/v1

License: (c) (i) This work is licensed under a Creative Commons Attribution 4.0 International License. Read Full License 


\section{Abstract}

Background: understanding molecular diversity in Lactuca species is substantial for the management, improvement and efficient uses of their accessions. Therefore, this work aimed to evaluate molecular diversity among and within Lactuca species.

Methods and Results: the molecular diversity was assessed using isozymes and RAPD analyses that gave $87.09 \%$ and $100 \%$ polymorphic percentages respectively, indicating a high genetic variation within and among Lactuca species. The number of alleles were higher in the wild species compared to the cultivated species, reflecting a reduction in the richness of alleles in the cultivated species due to domestication that caused a reduction in genetic diversity to meet the demand for high crop productivity. Isozymes and RAPD clustering dendrogrames: (1) separated, L. sativa accessions in more than one cluster confirming their polyphyletic origin; (2) collected the accessions of $L$. viminea in one cluster revealed its homogeneity; and (3) divided the accessions of $L$. saligna in two clusters varied in the number of alleles, particularly " $\mathrm{A}$ " form. The corresponding analysis associated the accessions of the wild species based on " $B$ " form of the alleles of the tested isozymes, and the cultivated species on the forms " $A$ " and "C", suggesting that: (1) allele "B" might be the primitive form of these loci that can tolerate the environmental stresses which prevails in the habitats of the wild species, and (2) forms " $\mathrm{A}$ " and " $\mathrm{C}$ " could be the derived forms.

Conclusions: These results are of great interest for the management of Lactuca germplasm and for future breeding programs of lettuce.

\section{Introduction}

Genus Lactuca L. is a member of subtribe Lactucinae, tribe Lactuceae, family Lactuceae (Asteraceae) (Güzel et al. 2018). It includes annual, biennial or perennial herbs, rarely shrubs with abundant latex. The species of Lactuca distributed mainly in warm and temperate geographical regions of the world (van Herwijnen and Manning 2017). However, the continents Asia and Africa are the center of the diversity of the genus. (Doležalová et al., 2002).

The primary gene pool of L. sativa L. is represented by a worldwide spread L. serriola, further L. aculeata, L. scarioloides, L. altaica, L. azerbaijancia, $L$. georgica originating in Asia and L. dregeana native to South Africa (Zohary 1991; van Herwijnen and Manning 2017). The secondary gene pool includes $L$. saligna, whereas the tertiary gene pool includes the species that can be crossed with difficulties with L. sativa, e.g. L. virosa (Doležalová et al. 2002; Jemelková et al. 2018).

Genetic diversity is the raw material permitting species to adapt to environmental changes. The genetic structure of accessions varies from niche to niche along the distribution range of a species (Mondini et al. 2009). So, estimating of genetic diversity is crucial for providing information for domestication, propagation, breeding programs, conservation and use of the germplasm of the plant species (Yu et al. 2001). Biochemical and Molecular markers have been proved as valuable tools to assess and evaluate genetic diversity between and within species, populations and accessions (Yang et al. 2013; Khan et al. 2019). Each marker reveals a specific class of variation, which is dependent on: (1) the fraction of the genome surveyed by that marker, (2) marker distribution throughout the genome and (3) the extent of the DNA target which is analyzed by that marker (Govindaraj et al. 2015; Bhandari et al. 2017).

Isozymes have been used as a reproducible marker in assessing the amount and distribution of genetic variability and systematic relationships within and between Lactuca spp. (Kesseli and Michelmore 1986; Dziechciarková et al. 2004). They exhibited that the genetic variability was lower in intra-species compared with inter-species and suggested that the origin of $L$. sativa was polyphyletic. The systematic relationship in Lactuca spp. was investigated using isozymes: (1) confirming the genetic closeness between $L$. aculeata and $L$. sativa as they are members of $L$. serriola complex, (2) revealing a wide genetic distance between L. saligna and L. virosa, and (3) identifying L. serriola, L. saligna, L. virosa, and landrace L. sativa as distinct entities (Kesseli and Michelmore 1986).

The use of molecular markers is also important in assessing the level of genetic diversity and in defining the genetic relationship between and within species, populations and accessions. Randomly Amplified Polymorphic DNA marker (RAPD) is one of the class of DNA markers that has received maximum attention in investigating the genetic variability because it is less expensive, less technical, fast and involves no radioactivity and hybridization. It was used to investigate the genetic variability and interspecific relationship among accessions, cultivars and genotypes of $L$. sativa indicating wide genetic base (Waycott and Fort 1994; Yoo and Jang 2003; Sharma et al. 2017).

Genetic resources collections of Lactuca species are poorly characterized because they are made up of large groups of numbered accessions of Lactuca that lack descriptive and (or) pedigree (Lebeda et al. 2019). So, little information is available on the genetic variation among different accessions of Lactuca representing different regions in the world. Therefore, the aim of this research was to use isozymes and DNA markers to evaluate the genetic variability and genetic relationships within and between Lactuca species.

\section{Material And Methods Plant materials}

The experimental material was obtained from the CGN (Centre for Genetic Resources, Wageningen, The Netherlands). The material was: (A) Lactuca sativa group Butterhead lettuce (CGN04706) from Netherlands, (B) Lactuca sativa group Butterhead lettuce (CGN04888) from USA, (C) Lactuca sativa group Crisp lettuce (CGN05048) from China, (D) Lactuca sativa group Latin lettuce (CG N04566) from France, (E) Lactuca sativa group Latin lettuce (CGN05835) from Spain, (F) Lactuca sativa group Latin lettuce (CGN04557) from Argentina, (G) Lactuca sativa group Cos lettuce (CGN04744) from Turkey, (H) Lactuca sativa group Cutting lettuce (CGN10956) from Italy, (I) Lactuca sativa group Stalk lettuce (CGN11387) from China, (J) Lactuca sativa group Stalk lettuce(CGN04546) from USA, (K) Lactuca serriola group Oilseed lettuce (CGN04770) from Egypt, (L) Lactuca serriola (CGN16210) from Germany, (M) Lactuca Loading [MathJax]/jax/output/CommonHTML/jax.js 
sativa_X_Lactuca serriola group Oilseed (CGN05115) from Egypt, (N) Lactuca saligna (CGN13330) from Turkey, (0) Lactuca saligna (CGN13327) from Greece, (P) Lactuca saligna (CGN10883) from Portugal, (Q) Lactuca virosa (CGN05332) from Italy, (R) Lactuca virosa (CGN05145) from France, (S) Lactuca indica (CGN14312) from Indonesia, (T) Lactuca indica (CGN13392) from China, (U) Lactuca viminea (CGN16202) from USSR, (V) Lactuca viminea (CGN14301) from France, (W) Lactuca dregeana (CGN04790) from Italy, (X) Lactuca dregeana (CGN05805) from France, (Y) Lactuca perennis (CGN09321) from Switzerland, (Z) Lactuca perennis (CGN13299) from France.

\section{Protein Extraction, Electrophoresis And Activity Staining}

Protein extraction, electrophoresis and activity staining Isozymes crude extracts were prepared by macerating $20 \mathrm{mg}$ young leaves of fifteen days old seedlings with $1 \mathrm{~mL}$ of extraction buffer consisted of $0.05 \mathrm{M}$ sodium phosphate buffer (pH 7.2), 20\% v/v glycerol, 14 mM 2-mercaptoethanol and 0.05\% v/v triton X-100 (Manchenko 1994). The clear supernatant was applied directly on $7 \%$ PAGE at $4^{\circ} \mathrm{C}$ in a Mini Protean III unit (BioRad, California, USA), under a constant current of $100 \mathrm{~mA}$ for 5 to $6 \mathrm{hr}$, until the tracking dye had moved 5 to $7 \mathrm{~cm}$ from the cathodal end. The gels were subjected to staining for Phosphorylase, Catalase, $a$-Esterase and $\beta$-Esterase isozymes following the protocols of Pasteur et al. (1988). Phosphorylase gels were stained in solution formed of $10 \mathrm{mM} \mathrm{I}_{2}$ mixed with $14 \mathrm{mM} \mathrm{KI}$ after incubation in $100 \mathrm{ml}$ solution of $0.1 \mathrm{M}$ sodium phosphate buffer $(\mathrm{pH} 5.1)$ at $37^{\circ} \mathrm{C}$ for 3 to $5 \mathrm{~h}$, developing white bands on a dark blue background. The chromatic or light brown bands appeared at the bottom of the gels were amylase bands. The gels of catalase were stained by immersing in 1:1 mixture of solutions $2 \%$ potassium ferricyanide and $2 \%$ ferric chloride after incubation in a solution of $3 \% \mathrm{H}_{2} \mathrm{O}_{2}$ for about $15 \mathrm{~min}$. The gels were then washed and gently agitated for a few minutes in water. Yellow bands of Catalase activity appeared on a blue-green background. The gels of a and $₫$-esterases were incubated at $37^{\circ} \mathrm{C}$ for 15 min in

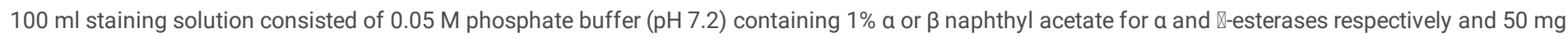
Fast Blue RR until brown colored bands appeared. The stained gels were photographed as quickly as possible and stored in $3 \%$ acetic acid. At least 5 and generally 10 plants per accession were examined for isozyme patterns.

\section{Dna Extraction For Rapd Analysis}

$0.5 \mathrm{~g}$ young leaves of fifteen days old seedlings were ground with a pestle in liquid nitrogen. The ground sample was suspended in $1 \mathrm{ml}$ preheated CTAB buffer (1.4 M NaCl, $0.2 \%$ 2-mercaptoethanol, $100 \mathrm{mM}$ Tris-Cl and $20 \mathrm{mM}$ EDTA) at $65^{\circ} \mathrm{C}$ for one hour. The suspended solution was centrifuge at $1000 \mathrm{rpm}$ and the supernatant was mixed with $0.5 \mathrm{ml}$ of $24: 1$ chloroform: isomyl, then centrifuge at $14000 \mathrm{rpm}$ (Doyle and Doyle 1990). The aqueous layer was mixed with ice cold isopropanol, then incubated overnight at $-20^{\circ} \mathrm{C}$ and centrifuged at $14000 \mathrm{rpm}$. The supernatant was discarded and the pellet which contained the nucleic acid was carefully washed twice with cold $70 \%$ ethanol, dried at room temperature and re-suspended in $100 \mu$ l of sterile de-ionized distilled water.

\section{Rapd Amplification}

Genomic DNAs of the studied accessions were amplified in $25 \mu$ reaction mixture, containing $20 \mathrm{ng}$ DNA, 0.5 unit Taq polymerase (Sigma-Aldrich, St. Louis, MO, USA), 0.2 mM PCR Nucleotide Mix (Boehringer Mannheim, Tubingen, Germany), $0.5 \mu \mathrm{M}$ RAPD primers, $5 \mu$ amplification buffer, $1.5 \mu \mathrm{l}$ of MgCl ${ }_{2}$ and $9.75 \mu \mathrm{l}$ of distilled $\mathrm{H}_{2} \mathrm{O}$ (Williams et al. 1990). Amplification was performed for 45 cycles using a Biometera Uno thermal cycler (SPW Industrial, Laguna Hills, CA, USA): One cycle at $95^{\circ} \mathrm{C}$ for 3 minutes, then 44 cycles at $92{ }^{\circ} \mathrm{C}$ for 2 minutes, $37{ }^{\circ} \mathrm{C}$ for 1 minute and $72^{\circ} \mathrm{C}$ for 2 minutes. The reactions were finally run at 72 ${ }^{0} \mathrm{C}$ for $10 \mathrm{~min}$ and further incubated on ice, at $4{ }^{\circ} \mathrm{C}$. The primers were chosen based on their ability to produce reproducible amplification patterns. The primers used were: OPA08 (5- GTGACGTAGG - 3), OPA09 (5- GGGT $\forall C G \mathbb{C}$ - 3), OPA14 (5- TCTGTGCTGG - 3), OPA20 (5- G T GCGATC - 3) and OPZ12 (5 - $T C \forall C G G G A C$ - 3). The amplification DNAs were separated by electrophoresis on $2 \%$ agarose in 50X Tris-Acetate EDTA buffer consisted of $242 \mathrm{~g}$ Tris-base, $57.1 \mathrm{ml}$ Glacial acetic acid and $100 \mathrm{ml}$ EDTA $(0.5 \mathrm{M} \mathrm{pH} 8.0)$. The electrophoresed gels were stained in $0.2 \mu \mathrm{g} / \mathrm{ml}$ ethidium bromide, then photographed under UV light. DNA ladder (Axygen, Union City, CA, USA) was run side by side with the samples, consisted of the following DNA fragments: 1031, 900, 800, 700, 600, $500,400,300,200$ and $100 \mathrm{bp}$

\section{Data analysis}

The isozymes and RAPD bands were scored as " 0 " for presence and " 1 ' for absence for a band at a particular locus in each accessions, which were transformed into a binary character matrix. The binary character matrix of each marker was subjected to correspondence and cluster analyses using the software package "PAST", Version 4.02, Natural History Museum, University of Oslo, 1999-2020. The cluster analyses were performed using the unweighted pair-group method with arithmetic mean (UPGMA).

\section{Results}

Isozymes analysis

The electrophoretic patterns of the four isozyme systems viz. phosphorylase, catalase, a- Esterase and $\beta$-Esterase in 26 accessions of Lactuca spp. exhibited 31 alleles (Table 1). 27 alleles were polymorphic and 4 were monomorphic (ACP-1A, ACP-4A, CAT-3A and aEST-4) with 87.09\% polymorphism (Table 1). Furthermore, the polymorphism in the accessions of L. sativa was $74.2 \%$. 
Table 1

The accession number and the origin of the studied accessions of Lactuca species

\begin{tabular}{|c|c|c|c|c|c|c|c|}
\hline Code & Species & $\begin{array}{l}\text { Accession } \\
\text { no. }\end{array}$ & Origin & Code & Species & $\begin{array}{l}\text { Accession } \\
\text { no. }\end{array}$ & Origin \\
\hline A & Lactuca sativa group Butterhead lettuce & CGN04706 & Netherlands & $\mathrm{N}$ & Lactuca saligna & CGN13330 & Turkey \\
\hline B & Lactuca sativa group Butterhead lettuce & CGN04888 & USA & 0 & Lactuca saligna & CGN13327 & Greece \\
\hline C & Lactuca sativa group Crisp lettuce & CGN05048 & China & $\mathrm{P}$ & Lactuca saligna & CGN10883 & Portugal \\
\hline D & Lactuca sativa group Latin lettuce & CGN04566 & France & Q & Lactuca virosa & CGN05332 & Italy \\
\hline $\mathrm{E}$ & Lactuca sativa group Latin lettuce & CGN05835 & Spain & $\mathrm{R}$ & Lactuca virosa & CGN05145 & France \\
\hline $\mathrm{F}$ & Lactuca sativa group Latin lettuce & CGN04557 & Argentina & S & Lactuca indica & CGN14312 & Indonesia \\
\hline G & Lactuca sativa group Cos lettuce & CGN04744 & Turkey & $\mathrm{T}$ & Lactuca indica & CGN13392 & China \\
\hline $\mathrm{H}$ & Lactuca sativa group Cutting lettuce & CGN10956 & Italy & U & Lactuca viminea & CGN16202 & $\begin{array}{l}\text { Union of } \\
\text { Soviet }\end{array}$ \\
\hline 1 & Lactuca sativa group Stalk lettuce & CGN11387 & China & V & Lactuca viminea & CGN14301 & France \\
\hline $\mathrm{J}$ & Lactuca sativa group Stalk lettuce & CGN04546 & USA & W & $\begin{array}{l}\text { Lactuca } \\
\text { dregeana }\end{array}$ & CGN04790 & Italy \\
\hline K & Lactuca serriola group Oilseed lettuce & CGN04770 & Egypt & $x$ & $\begin{array}{l}\text { Lactuca } \\
\text { dregeana }\end{array}$ & CGN05805 & France \\
\hline L & Lactuca serriola & CGN16210 & Germany & $\mathrm{Y}$ & Lactuca perennis & CGN09321 & Switzerland \\
\hline M & $\begin{array}{l}\text { Lactuca sativa_x_ Lactuca serriola group } \\
\text { Oilseed }\end{array}$ & CGN05115 & Egypt & Z & Lactuca perennis & CGN13299 & France \\
\hline
\end{tabular}

The number of alleles ranged from 17 in L. virosa CGN05145 from France to 27 in L. sativa x L. serriola group Oilseed CGN05115 from Egypt with an average 20.8 and the mean number of alleles per locus ranged from 0.55 to 0.87 with an average 0.67 (Table 2). The mean frequency of alleles of the 26 accessions was 0.64 . It was higher in cultivated species (0.52) compared to the wild ones (0.48). The lowest allele frequency $(0.07)$ was observed for the allele $C A T-1 \mathrm{~A}$ in the accessions of L. perennis. 
Table 2

Allelic frequencies for 16 isozyme loci in 26 accessions of Lactuca species.

\begin{tabular}{|c|c|c|c|c|c|c|c|c|c|c|c|c|c|c|c|c|c|c|c|c|}
\hline Code & \multicolumn{2}{|c|}{$\begin{array}{l}\text { Allele } \\
\text { Frequency }\end{array}$} & A & B & $C$ & D & $E$ & $F$ & G & H & I & $\mathbf{J}$ & $\mathrm{K}$ & L & $M$ & $\mathbf{N}$ & 0 & $P$ & $\mathbf{Q}$ & $F$ \\
\hline 1 & $\begin{array}{l}\text { ACP- } \\
1\end{array}$ & A & 1 & 1 & 1 & 1 & 1 & 1 & 1 & 1 & 1 & 1 & 1 & 1 & 1 & 1 & 1 & 1 & 1 & 1 \\
\hline 2 & \multirow{3}{*}{$\begin{array}{l}\text { ACP- } \\
2\end{array}$} & $A$ & 0.25 & 0.33 & 0.5 & 0.5 & 0 & 0 & 0.5 & 0 & 0.5 & 0.67 & 0 & 0.33 & 0.4 & 0.4 & 0 & 0 & 0 & 0 \\
\hline 3 & & B & 0.75 & 0.5 & 0.33 & 0.5 & 0.37 & 0.67 & 0.5 & 0.67 & 0.5 & 0.33 & 0.67 & 0.67 & 0.2 & 0.6 & 0.37 & 0.5 & 1 & 1 \\
\hline 4 & & C & 0 & 0.17 & 0.17 & 0 & 0.63 & 0.33 & 0 & 0 & 0 & 0 & 0.33 & 0 & 0.4 & 0 & 0.63 & 0.5 & 0 & 0 \\
\hline 5 & \multirow{2}{*}{$\begin{array}{l}\text { ACP- } \\
3\end{array}$} & $A$ & 1 & 0.33 & 0.67 & 0.2 & 1 & 0.33 & 1 & 1 & 0 & 0.33 & 0.67 & 0.67 & 0.5 & 0.2 & 1 & 1 & 0 & 1 \\
\hline 6 & & $B$ & 0 & 0.67 & 0.33 & 0.8 & 0 & 0.67 & 0 & 0 & 1 & 0.67 & 0.33 & 0.33 & 0.5 & 0.8 & 0 & 0 & 1 & 0 \\
\hline 7 & $\begin{array}{l}\text { ACP- } \\
4\end{array}$ & A & 1 & 1 & 1 & 1 & 1 & 1 & 1 & 1 & 1 & 1 & 1 & 1 & 1 & 1 & 1 & 1 & 1 & 1 \\
\hline 8 & CAT-1 & $A$ & 0 & 0 & 0 & 0 & 0 & 0 & 0 & 0 & 0 & 0 & 0 & 0 & 0 & 0 & 0 & 0 & 0 & 0 \\
\hline 9 & CAT-2 & A & 0 & 0.67 & 0.67 & 1 & 0 & 1 & 0.33 & 0 & 1 & 0.67 & 0.67 & 0.5 & 0.6 & 1 & 0 & 0 & 0 & 0 \\
\hline 10 & & B & 1 & 0.33 & 0.33 & 0 & 1 & 0 & 0.67 & 1 & 0 & 0.33 & 0.33 & 0.5 & 0.4 & 0 & 1 & 1 & 1 & 1 \\
\hline 11 & CAT-3 & $A$ & 1 & 1 & 1 & 1 & 1 & 1 & 1 & 1 & 1 & 1 & 1 & 1 & 1 & 1 & 1 & 1 & 1 & 1 \\
\hline 12 & CAT-4 & $A$ & 0.37 & 0.5 & 0.5 & 0.5 & 0 & 0 & 0.5 & 0 & 0.5 & 0.33 & 0.17 & 0.5 & 0.4 & 0.3 & 0 & 0 & 0 & 0 \\
\hline 13 & & B & 0.63 & 0.17 & 0.17 & 0.5 & 0.63 & 0.67 & 0.5 & 0.5 & 0.5 & 0.67 & 0.5 & 0.5 & 0.2 & 0.7 & 0.63 & 0.67 & 1 & 1 \\
\hline 14 & & C & 0 & 0.33 & 0.33 & 0 & 0.37 & 0.33 & 0 & 0.5 & 0 & 0 & 0.33 & 0 & 0.4 & 0 & 0.37 & 0.33 & 0 & 0 \\
\hline 15 & aEST- & A & 1 & 1 & 1 & 1 & 1 & 1 & 1 & 1 & 1 & 1 & 1 & 1 & 0 & 0.6 & 0.37 & 0.5 & 0.33 & 0 \\
\hline 16 & & B & 0 & 0 & 0 & 0 & 0 & 0 & 0 & 0 & 0 & 0 & 0 & 0 & 1 & 0.4 & 0.63 & 0.5 & 0.67 & 0 \\
\hline 17 & aEST- & A & 0.5 & 0.5 & 0.5 & 0.5 & 0 & 0 & 0.5 & 0 & 0.5 & 0.5 & 0.17 & 0.5 & 0.5 & 0.5 & 0 & 0 & 0 & 0 \\
\hline 18 & & B & 0.5 & 0 & 0 & 0.5 & 0.5 & 0.5 & 0.5 & 0.5 & 0.5 & 0.5 & 0.5 & 0.5 & 0 & 0.5 & 0.5 & 0.5 & 1 & 1 \\
\hline 19 & & C & 0 & 0.5 & 0.5 & 0 & 0.5 & 0.5 & 0 & 0.5 & 0 & 0 & 0.33 & 0 & 0.5 & 0 & 0.5 & 0.5 & 0 & 0 \\
\hline 20 & $\begin{array}{l}\mathrm{aEST}- \\
3\end{array}$ & A & 1 & 0 & 0.33 & 0 & 1 & 0 & 1 & 1 & 0 & 0 & 0.5 & 0.5 & 0.5 & 0 & 1 & 1 & 1 & 1 \\
\hline 21 & & B & 0 & 1 & 0.67 & 1 & 0 & 1 & 0 & 0 & 1 & 1 & 0.5 & 0.5 & 0.5 & 1 & 0 & 0 & 0 & 0 \\
\hline 22 & $\begin{array}{l}\mathrm{aEST}- \\
4\end{array}$ & A & 1 & 1 & 1 & 1 & 1 & 1 & 1 & 1 & 1 & 1 & 1 & 1 & 1 & 1 & 1 & 1 & 1 & 1 \\
\hline 23 & $\beta$ EST- & A & 0 & 0 & 0 & 0 & 0 & 0 & 0 & 0 & 0 & 0 & 0 & 0 & 0 & 0 & 0 & 0 & 0 & 0 \\
\hline 24 & & B & 0 & 0 & 0 & 0 & 0 & 0 & 0 & 0 & 0 & 0 & 0 & 0 & 1 & 1 & 1 & 1 & 1 & 1 \\
\hline 25 & $\beta E S T-$ & $A$ & 0.63 & 0.5 & 0.67 & 0.5 & 0.33 & 0.33 & 0.5 & 0.33 & 0.67 & 0.33 & 0.67 & 0.5 & 0.25 & 0.5 & 0.63 & 0.5 & 0.83 & 0 \\
\hline 26 & & B & 0.37 & 0.5 & 0.33 & 0.5 & 0.67 & 0.67 & 0.5 & 0.67 & 0.33 & 0.67 & 0.33 & 0.5 & 0.75 & 0.5 & 0.37 & 0.5 & 0.17 & 0 \\
\hline 27 & $\beta E S T-$ & A & 0.5 & 0.5 & 0.5 & 0.4 & 0 & 0.33 & 0.67 & 0.17 & 0.5 & 0.33 & 0.17 & 0.33 & 0.5 & 0.5 & 0 & 0 & 0 & 0 \\
\hline 28 & & B & 0.5 & 0 & 0 & 0.6 & 0.5 & 0.5 & 0.33 & 0.33 & 0.5 & 0.67 & 0.5 & 0.67 & 0.2 & 0.5 & 0.5 & 0.5 & 0.67 & 1 \\
\hline 29 & & $C$ & 0 & 0.5 & 0.5 & 0 & 0.5 & 0.17 & 0 & 0.5 & 0 & 0 & 0.33 & 0 & 0.3 & 0 & 0.5 & 0.5 & 0.33 & 0 \\
\hline 30 & $\beta_{4}$ EST- & A & 0.25 & 0.67 & 0.67 & 0.8 & 0.25 & 1 & 0.33 & 0 & 0.67 & 1 & 0.67 & 0.67 & 0.6 & 1 & 0 & 0 & 0 & 0 \\
\hline 31 & & B & 0.75 & 0.33 & 0.33 & 0.2 & 0.75 & 0 & 0.67 & 1 & 0.33 & 0 & 0.33 & 0.33 & 0.4 & 0 & 1 & 1 & 1 & 1 \\
\hline & $\begin{array}{l}\text { Total } \\
\text { numbe } \\
\text { alleles }\end{array}$ & & 20 & 24 & 25 & 21 & 20 & 21 & 21 & 19 & 20 & 21 & 26 & 23 & 27 & 22 & 22 & 21 & 18 & 1 \\
\hline & $\begin{array}{l}\text { Mean } \\
\text { Numbe } \\
\text { of allel } \\
\text { per loc }\end{array}$ & & 0.65 & 0.77 & 0.80 & 0.68 & 0.65 & 0.68 & 0.68 & 0.61 & 0.65 & 0.68 & 0.84 & 0.74 & 0.87 & 0.71 & 0.71 & 0.68 & 0.58 & 0 \\
\hline
\end{tabular}

* Average of mean frequency of allele

The clustering dendrogram of the isozymes data gave two main groups (G1 and G2) at genetic distances 2.25 (Fig. 1). The accessions of $L$. sativa were distributed in the two groups (Fig. 1). G1 included L. serriola group Oilseed lettuce, L. serriola, L. sativa x L. serriola group Oilseed and six accessions of $L$. Loading [MathJax]/jax/output/CommonHTML/jax.js - dregeana with the rest of the accessions of L. sativa. At genetic distances 1.9, Lactuca accessions were 
separated into five clusters and two singletons (L. sativa x L. serriola group Oilseed (CGN05115) and L. perennis CGN13299). Cluster one (C1) contained the accessions of $L$. indica and $L$. perennis CGN09321, whereas C2 included $L$ sativa (group Butterhead lettuce CGN04888, group Crisp lettuce CGN05048, group Latin lettuce CGN04566, group Latin lettuce CGN04557, group Cos lettuce CGN04744 and group Stalk lettuce CGN11387), L. serriola group Oilseed lettuce CGN04770, L. serriola CGN16210 and L. saligna CGN13330. L. saligna CGN13327, L. saligna CGN10883 and the accessions of L. viminea were collected in C3. The accessions of $L$. virosa and L. dregeana were separated in C4. L. sativa group Butterhead lettuce CGN04706, L. sativa group Latin lettuce CGN05835, L. sativa group Cos lettuce CGN04744 and L. sativa group Cutting lettuce CGN10956 were grouped in C5.

The accessions in the top right quadrant of the corresponding analysis of the isozyme data included $L$. sativa group Butterhead lettuce CGN04888, $L$. sativa group Crisp lettuce CGN05048, L. sativa group Latin lettuce CGN04566, L. sativa group Latin lettuce CGN04557, L. sativa group Cos lettuce CGN04744, L. sativa group Stalk lettuce CGN04546, L. serriola group Oilseed lettuce CGN04770, L. serriola CGN16210, L. sativa x L. serriola group Oilseed CGN05115, L. perennis CGN13299 (Fig. 2). These accessions were closely associated by the alleles, namely CAT-1A, CAT-2A, CAT-4A, aEST-1A, aEST-2A, aEST-3B and $\beta E S T$ $3 A$ (Fig. 2). The left top quadrant consisted of the accessions ( $L$. sativa group Butterhead lettuce CGN04706, $L$. sativa group Latin lettuce CGN05835, $L$. sativa group Cutting lettuce CGN10956 and the accessions of $L$. viminea) with the alleles ACP-2C, ACP-3A, CAT-4C, aEST-2C, $\beta E S T-1 \mathrm{~A}, \beta E S T-2 \mathrm{~A}$ and $\beta E S T-3 C$. The right bottom quadrant comprised the accessions L. saligna (CGN13330, L. indica CGN14312, L. indica CGN13392, L. perennis CGN09321) that were closely associated with ACP-2B, ACP-3B, CAT-4B, aEST-2B, $\beta E S T$-2B, $\beta E S T$-3B. The accessions (L. saligna CGN13327, L. saligna CGN10883, L. virosa CGN05332, L. virosa CGN05145, L. dregeana GN04790, L. dregeana CGN05805) in the bottom left were also closely related in terms of CAT-2B, aEST-1B, aEST-3A, $\beta E S T-1 \mathrm{~B}$, $\beta E S T$ - 4B.

\section{Rapd Analysis}

Among 18 random primers tested in this study, 5 primers generated reproducible bands. A total of 186 polymorphic bands were identified using the five primers. Maximum and minimum percentages of polymorphic bands were observed by primers OPA3 (46 fragments) and OPA1 (31 fragments) respectively. The average percentage of polymorphic bands was $100 \%$. The average size of DNA fragments ranged between 33bp and 600bp (Fig. 3). The fragment with DNA size of: 33 bp is unique marker for L. sativa x L. serriola group Oilseed CGN05115; 500 bp DNA fragment for L. indica CGN13392 (Primer 1 OPA09); 200 bp DNA fragment for L. serriola group Oilseed lettuce CGN04770; 500 bp DNA fragment for L. serriola group Oilseed lettuce CGN04770 (Primer 2 OPA14); 200 bp DNA DNA fragment for L. serriola group Oilseed lettuce CGN04770; 350 bp DNA fragment for L. saligna CGN13330, 47 bp DNA fragments for L. saligna CGN10883 (Primer 3 OPZ12).

The clustering dendrogram constructed based on RAPD results showed seven clusters (C1-C7) (Fig. 4). The first and second clusters (C1 and C2) included $L$. serriola group Oilseed lettuce CGN04770 and all the accessions of L. sativa except L. sativa group Butterhead CGN04706 which was separated as singleton at far genetic distance. The wild species L. serriola CGN16210 and L. sativa x L. serriola group Oilseed CGN05115 were clustered in C7 which is connected with other accessions at genetic distance 7.5. The accessions of L. viminea, L. dregeana and L. perennis were included in C5. The accessions of Lactuca saligna (C3 and C6), L. virosa (C3 and C4) and L. indica (C4 and C5) were distributed in two clusters. It can be noticed that two accessions of Lactuca saligna (Lactuca saligna CGN13327 from Greece and Lactuca saligna CGN10883 from Portugal) were collected with Lactuca serriola and Lactuca sativa $x$ Lactuca serriola group Oilseed and the third accession (Lactuca saligna CGN13330 from Turkey) was clustered with Lactuca virosa and Lactuca indicia.

\section{Discussion}

Estimating the genetic diversity between and within accessions of crop species and its wild relatives assist in decision-making to select the best accessions for selection of parents for hybridization and is crucial for providing information for domestication and propagation (Yu et al. 2001; Khan et al. 2019). It is also enhancing the understanding of the plant germplasm for germplasm management and potential users, and helping in producing new varieties best adapted to regional environmental conditions (El-Esawi, et al. 2017; van Herwijnen and Manning 2017).

In the present study, the estimation of genetic diversity with isozyme markers showed high polymorphism between the examined accessions (87.09\%) which was attributed to outcrossing of the majority of the species and infrequent interspecific hybridization (Jemelková, et al. 2018). It also showed that the polymorphism between L. sativa accessions (74.2\%) was not with same magnitude of the polymorphism between the wild species, reflecting the impact of domestication (successive rounds of selection) on reducing the genetic diversity of the domesticated species, leaving them with less allelic richness than their wild progenitors and other crop wild relatives (Abbo et al. 2014; Dempewolf et al. 2017).

The highest number of alleles in the wild species (31) compared with the cultivated species $L$. sativa (27) reflected a reduction in the richness of alleles due to domestication which was reported to modify agronomic phenotypes and genetic signature of the domesticated species, resulted in the reduction in genetic diversity to meet the demand for high crop productivity and crop uniformity in the field and the marketplace (Dempewolf et al. 2017; Zhang et al. 2017). The variation between cultivated and wild species was not only limited to the number of alleles, but also it extended to the mean frequency of alleles which was found to be higher in the cultivated species (0.52) comparing with the wild ones (0.48). This might be attributed to the absence of selection pressure on the wild species, as the existing variations in these species are natural (Das 2011). The allele with low mean allele frequency (0.07) or what was known as rare alleles was observed only for the allele CAT-1A in L. perennis. The presence of this allele could be due to deleterious mutations or may be due to evolutionary relics (Sammour et al. 2019). The detection of rare allele in combination with high allelic frequency of other loci leads to the conclusion that the studied accessions had wide genetic differentiation.

The separation of $L$. dregeana with $L$. virosa in the same cluster in isozymes and RAPD cluster analyses confirmed their closely relatedness as they belong to the same section Lactuca (Lebeda and Astley 1999), having one pair of satellites (El-Esawi and Sammour 2014) and similar morphological characters (De Loading [MathJax]/jax/output/CommonHTML/jax.js confirmed the very close relationship between L. serriola and L. dregeana and considered the two taxa to be 
conspecific based on AFLP fingerprints, nuclear and plastid DNA sequence comparison, isozymes and RAPD results of the present research recognized differences between them adequate to maintain them as distinct species, confirming the previous morphological, karyological, historical occurrence, and ecological studies (Zohary 1991; El-Esawi and Sammour 2014; van Herwijnen and Manning 2017).

The distribution of the accessions of $L$. sativa in more than one cluster in the isozymes and RAPD dendrograms confirmed the polyphyletic origin of $L$. sativa. Furthermore, the clustering of some of the accessions of L. sativa with L. serriola group Oilseed lettuce based on isozymes data and the clustering of the rest of the accessions with $L$. dregeana confirmed that $L$. serriola and $L$. dregeana were members of the primary gene pool of $L$. sativa (Zohary 1991$)$ and was consistent with the work of Kesselli and Michelmore (1986) who also suggested that domestication of L. sativa may be due to the repeated domestication from wild progenitors or may be due to the use of interspecific hybridizations in breeding programmes to introduce characters of interest into cultivated lettuce. However, the prevailing of the allele " $B$ " in the wild species and alleles " $A$ " and " $C$ " in the cultivated species and its progenitors, as it has been shown in the corresponding analysis, indicating that the cultivated species was firstly domesticated from wild progenitors and later breeders used interspecific hybridizations to introduce characters of interest into cultivated lettuce. The prevailing of the allele " $\mathrm{B}$ " in wild species and alleles " $\mathrm{A}$ " and " $\mathrm{C}$ " in cultivated ones also suggested that: (1) allele " $B$ " might be the primitive form of studied alleles that enable the wild species to resist the environmental stresses which prevails in their habitats, and (2) alleles " $\mathrm{A}$ " and "C" could be derived forms that evolved as a result of domestication.

The separation of the accessions of $L$. saligna in two clusters in the cluster analysis of the isozymes data was consistent with the works of Esawi et al. (2017). The heterogeneity of this species attributed to the difference in the number and types of alleles in the studied accessions. The accessions $L a c t u c a$ saligna CGN13327 from Greece and Lactuca saligna CGN10883 from Portugal did not have the allele "A" of the loci ACP-2, CAT-2, CAT-4, aEST-2, $\beta E S T-3$, $\beta E S T-4$ which characterize the cultivated species, whereas the accession Lactuca saligna CGN13330 from Turkey had these alleles. This lead to infer that the accession from Turkey might be subjected to a natural mutation or a sort of unintended domestication. Although Güzel et al. (2018) observed several samples in the field and herbaria belonging to $L$. viminea that easily fell into two distinct subspecies according to their habits and morphological traits, the clustering dendrograms of isozymes and RAPD analyses separated the accessions of $L$. viminea in one cluster which was inconsistent with their observation. The variation observed by Güzel et al. (2018) could be attributed ecogeographical conditions in which the accessions of $L$. viminea were originated; the conditions that cause a significant variation in the phenotypic characters. The clustering dendrogram based on RAPD data indicated a close genetic relationship between L. sativa, L. serriola, L. saligna and L. virosa which was consistent with the phylogenetic trees based on chloroplast DNA sequence comparison (Wei et al. 2017), chromosomal studies (Matoba et al. 2007), nrITS1 and AFLP fingerprints (Koopman et al. 2001). So, L. serriola, L. saligna and L. virosa can be considered important resources for L. sativa breeding.

\section{Conclusion}

Genetic variability was considerable high within and among Lactuca species based on isozymes or RAPD analyses, opened the path for the improvement of the cultivated species. The number of alleles were lower in the cultivated species compared to the wild species, reflecting a reduction in the richness of alleles in the cultivated species due to domestication. The cluster and corresponding analyses revealed: (1) the polyphyletic origin of $L$. sativa, (2) the homogeneity of the accessions of $L$. viminea ruling out the previous study showed that $L$. viminea has two distinct subspecies, (3) the grouping of the wild accessions based on the form "B" of the studied alleles and the cultivated accessions based on the forms "A" and "C", suggesting that form "B" might be the primitive form of the alleles of the loci of the assessed isozymes, and " $\mathrm{A}$ " and " $\mathrm{C}$ " could be the derived forms, and (4) the separating of the accessions of $L$. saligna in two clusters was due to the variation in the number of alleles, particularly " $\mathrm{A}$ " form, suggesting that some accessions could be wild and the other might be subjected to natural mutation or unintended domestication. The accessions of L. sativa x L. serriola group Oilseed, L. indicia, L. saligna were characterized with unique DNA fragments that can be used as markers for identifying these accessions. The association between specific forms of alleles and both cultivated and wild species needs deep insights to be manipulated for lettuce improvement. The considerable genetic variation in the accessions of Lactuca saligna, Lactuca virosa and Lactuca indica open the door for more detailed studies on big number of accessions cover their distribution range using multiple markers.

\section{Declarations}

\section{Acknowledgment}

This project was supported by King Saud University, Deanship of Scientific Research, College of Science, Research Center, Saudi Arabia.

\section{Compliance with ethical standards}

Conflict of interest The authors declare that there are no conflicts of interest.

\section{Authors' contributions}

This study was conceived and designed by R.H.S and M. E-M. Data were collected by M E-M. and validated by R.H.S and A.M. The initial draft was edited by M E-M and A.M. The revision and the final draft were edited by R.H.S.

\section{Consent to publication}

The authors are consent to publish this work in Molecular Biology Reports

\section{Consent to participate}

Loading [MathJax]/jax/output/CommonHTML/jax.js 
The authors are consent to participate in this manuscript.

\section{References}

Abbo S, van-Oss RP, Gopher A, Saranga Y, Ofner I, Peleg Z (2014) Plant domestication versus crop evolution: a conceptual framework for cereals and grain legumes. Trends Plant Sci. 19:351-360

Bhandari HR, Bhanu AN, Srivastava K, Singh MN, Hemantaranjan SA (2017) Assessment of genetic diversity in crop plants - an overview. Advances in Plants \& Agriculture Research 7:279-286

Das S (2011) Systematics and taxonomic delimitation of vegetable, grain and weed amaranths: a morphological and biochemical approach. Genetic Resources and Crop Evolution 59: $289-303$

De Candolle A (1838) Prodromus Systematics Naturalis Regni Vegetabilis, Paris

Dempewolf H, Baute G, Anderson J, Kilian B, Smith C, Guarino L (2017) Past and future use of wild relatives in crop breeding. Crop science 57:1070-1082

Doležalová I, Křístková E, Lebeda A, Vinter V (2002) Description of morphological characters of wild Lactuca L. spp. genetic resources (English-Czech version). Hort. Sci. Prague 29:56-83

Doyle J, Doyle L (1990) Isolation of plant DNA from fresh tissue. Focus 12:13-15

Dziechciarková M, Lebeda A, Doležalová I, Kristkova E (2004) Isozyme variation in European Lactuca serriola germplasm. Genet. variat. Plant breed. proceed. $17^{\text {th }}$ Eucarpia General Congress, Tullen, Austria 103-107

El-Esawi MA, Mustafa A-E, Badr S, Sammour R (2017) Isozyme analysis of genetic variability and population structure of Lactuca L. germplasm. Biochemical Systematics and Ecology 70:73-79

El-Esawi MA, Sammour R (2014) Karyological and phylogenetic studies in the genus Lactuca L. (Asteraceae). Cytologia 79:269-275

Govindaraj M, Vetriventhan M, Srinivasan M (2015) Importance of Genetic Diversity Assessment in Crop Plants and Its Recent Advances: An Overview of Its Analytical Perspectives. Genetics Research International, http://dx.doi.org/10.1155/2015/431487

Güzel ME, Kilian N, Gültepe M, Kandemir A, Coşkunçelebi k (2018) Contributions to the taxonomy of Lactuca (Asteraceae) in Turkey. Turkish Journal of Botany 42:197-207

Jemelková M, Kitner M, Kř́stková E, Doležalová I, Lebeda A (2018) Genetic variability and distance between Lactuca serriola L. populations from Sweden and Slovenia assessed by SSR and AFLP markers. Acta Bot. Croat. 77:172-180

Kesseli RV, Michelmore RW (1986) Genetic variation and phylogenies detected from isozyme markers in species of Lactuca. Journal of Heredity 77:324-331

\section{Khan MKU, Muhammad N, Uddin N, Ali N, Khan I, Ullah R (2019) Genetic polymorphism within the wild population of Rhynchosia himalensis Benth. ex Baker. International Journal of Biosciences14:54-64}

Koopman WJM, Zevenbergen MJ, Van den Berg RG (2001) Species relationships in Lactuca s.I. (Lactuceae, Asteraceae) inferred from AFLP fingerprints. Am. J. Bot. 88:1881-1887

Lebeda A, Astely D (1999) World genetic resources of Lactuca spp., their taxonomy and biodiversity. In: Lebeda A, Kristkova E (eds.): Eucarpia leafy vegetables '99. Palacky Univ., Olomouc, CR: 81-94

Lebeda A, Křístková V, Kitner M, Majeský L, Doležalová I, Khoury CK, Widrlechner MP, Hu J, Carver D, Harold A. HA, C. Sosa CC (2019) Research Gaps and Challenges in the Conservation and Use of North American Wild Lettuce Germplasm. Crop Sci. 59:2337-2356

Manchenko G (1994) Handbook of Detection of Enzymes on Electrophoretic Gels. CRC Press, Inc

Matoba H, Mizutani T, Nagano K, Hoshi Y, Uchiyama H (2007) Chromosomal study of lettuce and its allied species (Lactuca spp., Asteraceae) by means of karyotype analysis and fluorescence in situ hybridization. Hereditas 144:235-247

Mondini L, Noorani A, Mario A, Pagnotta MA (2009) Assessing Plant Genetic Diversity by Molecular Tools. Diversity 1:19-35

Pasteur N, Pasteur G, Bonhomme F, Catalan J, Britton-Davidiaan J, Cobb M (1988) Practical Isozyme Genetics. Ellis Horwood Limited, Chichester, England

Sammour RH, Fahmee S, Mustafa A-E, Taher W (2019) Isozyme analysis of genetic variability and population structure of Lathyrus sativus L. germplasm. Legume Research 42:1-7

Sharma S, Kumar P, Gambhir G, Kumar R, Srivastava DK (2017). Assessment of genetic diversity in lettuce (Lactuca sativa L.) germplasm using RAPD markers. 3 Biotech 8:9, https://www.researchgate.net/publication/321729136

Loading [MathJax]/jax/output/CommonHTML/jax.js 
van Herwijnen ZO, Manning JC (2017) A review of the history and taxonomy of the enigmatic southern African endemic wild lettuce Lactuca dregeana DC. (Asteraceae: Lactuceae: Lactucinae). South African Journal of Botany 108:352-358

Waycott W, Fort S (1994) Differentiation of nearly identical germplasm accessions by a combination of molecular and morphological analyses. Genome 85:239-244

Wei Z, Zhu S-X, Van den Berg RG (2017) Phylogenetic relationships within Lactuca L. (Asteraceae), including African species, based on chloroplast DNA sequence comparison. Genetic Resources and Crop Evolution 64:55-71

Williams J, Kubelik A, Livak K, Rafalski J, Tingey S (1990) DNA polymorphisms amplified by arbitrary primers are useful as genetic markers. Nucleic Acids Res. 18:6531-6535

Yamamoto T, Nishikawa A, Oeda K (1994) DNA polymorphisms in Oryza sativa L. and Lactuca sativa L. amplified by arbitrary primed PCR. Euphytica 78:143148

Yang W, Kang X, Yang Q, Lin Y, Fang M (2013) Review on the development of genotyping methods for assessing farm animal diversity. J Anim. Sci. Biotechnology 4:1-10

Yoo K, Jang S (2003) Intraspecific relationships of Lactuca sativa var. capitata cultivars based on RAPD analysis. Korean J. Hort. Sci. Tech. 21:273-278

Yu J, Mosjidis J, Klingler K, Woods F (2001) Isozyme Diversity in North American Cultivated Red Clover. Crop Sci. 41:1625-1628

Zhang J, Wang X, Yao J, Li Q, Liu F, Yotsukura N, Krupnova TN, Delin Duan D (2017) Effect of domestication on the genetic diversity and structure of Saccharina japonica populations in China. Scientific Reports 7:42158 | DOI: 10.1038/srep42158

Zohary D (1991) The wild genetic resources of cultivated lettuce (Lactuca sativa L.). Euphytica 53:31-35

\section{Figures}
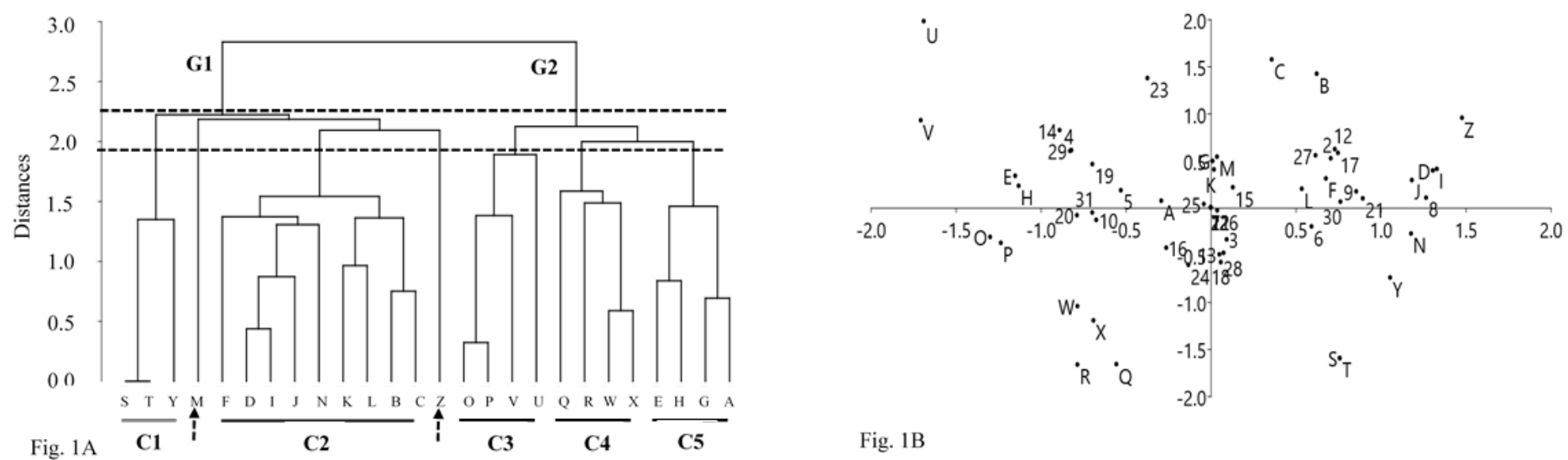

Fig. 1B

\section{Figure 1}

A. UPGMA clustering of 26 accessions of Lactuca species based on isozymes data. B. Corresponding analysis of 26 accessions of Lactuca spp. based on their isozymes characteristics explained by the first and second principal components. 


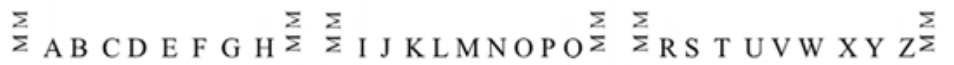
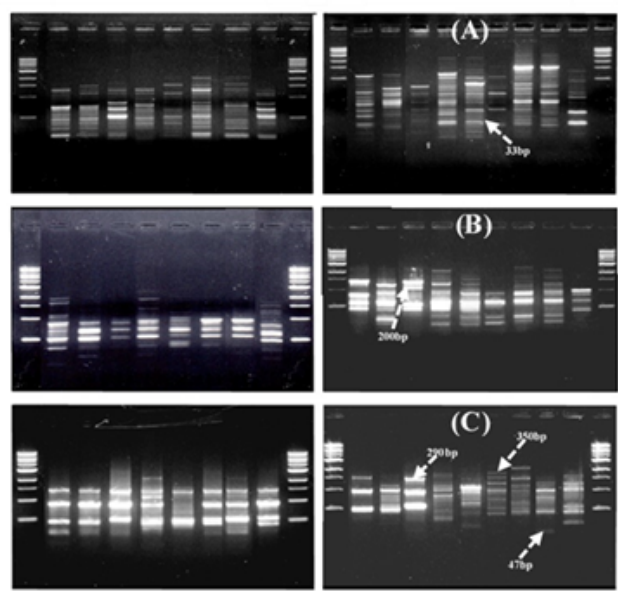

Fig. 2A
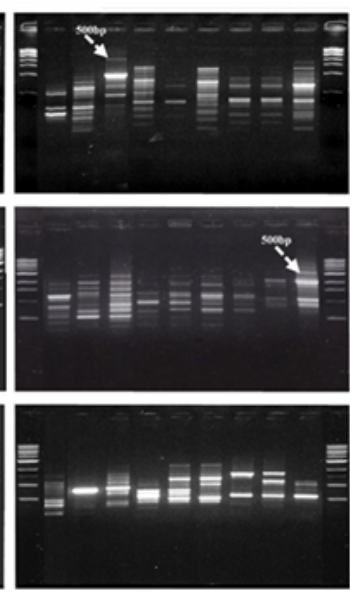

Figure 2

A. RAPD profiles of 26 accessions of Lactuca species produced by primer OPA09 (A), primer OPA14 (B), primer OPZ12 (C). The arrows indicates accession specific marker. B. UPGMA dendrogram of 26 accessions of Lactuca species based on RAPD marker data. 